\title{
Securitisation and Tranching Longevity and House Price Risk for Reverse Mortgage Products
}

\author{
Sharon S. Yang \\ Department of Finance, National Central University, Taoyuan 116, Taiwan.
}

Reverse mortgage (RM) products are growing increasingly popular in many developed countries. This article designs a tranching security to deal with longevity and house price risks for RM products. The securitisation structure for RM products, the collateralised reverse mortgage obligation (CRMO), is similar to that for the collateralised debt obligation (CDO). However, unlike the CDO, the CRMO takes into account the dynamics of future mortality rates and house price returns instead of the default rate. To capture longevity risk for RM borrowers, this study employs the CBD model to project future mortality rates, as well as compares these results with those from the Lee-Carter model and static mortality table. The house price return dynamics is modelled using an ARMAGARCH process. The calculation of fair spreads of CRMO in different tranches is illustrated under the risk-neutral valuation framework. On the basis of mortality experience and the programme of Home Equity Conversion Mortgage in the United States, this research demonstrates the problems of using static mortality tables and models risk for pricing fair spreads for CRMO numerically.

The Geneva Papers (2011) 36, 648-674. doi:10.1057/gpp.2011.26

Keywords: reverse mortgage; securitisation; CDO

\section{Introduction}

Human longevity has been increasing significantly since the start of the $20^{\text {th }}$ century. Whether human longevity will continue to improve in the future is debatable. The view that longevity will continue to increase is supported by mortality experiences in many developed and developing countries. ${ }^{1}$ Thus, how to increase retirement income to maintain the living standards of the elderly has become an important issue. The pension system has been the main financial resource for the elderly. Owing to the phenomenon of ageing populations and increases in longevity, the pension and annuity providers have suffered substantial financial problem, and therefore have started to reduce pension benefits in response. ${ }^{2}$ Governments also face great challenges in their efforts to finance their ageing populations. Thus, innovative financial products in the private market that might increase retirement income would be welcome.

In this context, home equity may be a viable option, in that it represents a major asset for people in many countries at retirement. For example, in

\footnotetext{
${ }^{1}$ Tuljapurkar et al. (2000), Blake et al. (2008), Yang and Huang (2009).

${ }^{2}$ Antolin (2007), Bauer and Weber (2007).
} 
Australia, ${ }^{3}$ total owner occupied home equity was AUD\$887 billion, and those older than 60 years owned AUD\$345 billion (39 per cent) of this amount; in the United States, the American Housing Survey ${ }^{4}$ has indicated that more than 12.5 million elderly have no mortgage debt, and the median value of these mortgage-free homes is US $\$ 127,959$. Reverse mortgage (RM) products that allow older people to convert their home equity into cash thus have been introduced to provide retirement income in many developed countries. Loans made through a reverse mortgage accrue with interest and are settled only upon the death of the borrower, sale of the property or tenure surrender. Thus, reverse mortgages are the opposite of traditional mortgages in the sense that the borrower receives payments from the lender instead of making such payments to the lender. In the United States, the Housing and Community Development Act of 1987 authorised the Home Equity Conversion Mortgage Program (HECM) in the Department of Housing and Urban Development (HUD) as a demonstration programme. It was the first nationwide RM programme in the U.S. Kutty ${ }^{5}$ has predicted that the use of RM products could raise about 29 per cent of impoverished, elderly U.S. homeowners above the poverty line. In addition, RM products have spread throughout the United Kingdom, Australia, Singapore and Japan.

Owing to demographic change globally, the market for reverse mortgage has grown rapidly recently. According to the National Reverse Mortgages Lenders Association, around 7,000 new HECM loans originated in year 2000. During 2009 alone, this increases to around 115,000 of HECM approvals, representing a 1640 per cent increase in the last 10 years. The growth continued in 2005 when 43,131 HECM reverse mortgages were approved. ${ }^{6}$ Australia has grown rapidly recently by both number of loans and size of loans. As on December 2008, there were 37,350 loans on issue with a loan amount outstanding of AUD\$2.48 billion. This compared with just 9,700 loans on issue with a loan amount outstanding of AUD\$0.459 billion as on December 2004 . $^{7,8}$ However, there are also some large barriers to the growth of the RM market, including high costs, moral hazard and adverse selection, financial awareness and literacy, perception of housing equity as a safety net for large medical expenses, bequest motives, and the difficulties associated with RM securitisation. ${ }^{9}$

However, reverse mortgages differ from traditional mortgages in the manner that the loans and accrued interests are repaid, which occurs only when the borrower dies or leaves the house. Unlike traditional mortgage pools, the credit risk in RM pools is not driven by potential default on the loans. The main risk factors instead are mortality, interest rates and the value of the underlying property. If a borrower lives

\footnotetext{
${ }^{3}$ Senior Australians Equity Release Association of Lenders Industry Submission, 2005.

${ }^{4}$ American Housing Survey for the United States (2005), Current Housing Reports, H150/05. U.S. Department of Housing and Urban Development and U.S. Census Bureau, August 2006, P156.

${ }^{5}$ Kutty (1998).

${ }^{6}$ See U.S. Department of Housing and Urban Development, FHA Outlook: 2003-2006.

${ }^{7}$ See Senior Australians Equity Release Association of Lender (SEQUAL), An Australian Consumer Law, March, 2009.

${ }^{8}$ Please also refer to Sun (2009) for the detailed market landscape regarding reverse mortgage products.

${ }^{9}$ Shan (2008).
} 
longer than expected or the house prices decrease, the principal advances and interest accruals may drive the loan balance higher than the potential proceeds of the sale of the property. Thus, a reverse mortgage is a longevity-dependent asset, and managing potential longevity risk is critical for mortgage providers. Traditional methods for dealing with RM risks include using insurance or writing no-negative guarantees; for example, the HECM program in the United States. At loan origination, borrowers are required to pay an upfront mortgage insurance premium (MIP) of 2 per cent of the maximum mortgage amount. In addition, borrowers pay an annual insurance premium of 0.5 per cent of the loan balance. ${ }^{10}$ Lenders thus are somewhat protected against losses that would arise if the loan balance exceeded the home's equity value at the time of settlement. Chen et al. ${ }^{11}$ investigate the sustainability of the HECM programmes in the U.S. by comparing the price of the non-recourse provision of reverse mortgages with calculated mortgage insurance premiums. In Britain, most of the roll-up mortgages are sold with a no-negative-equity-guarantee (NNEG) that protects the borrower by capping the redemption amount of the mortgage at the lesser of the face amount of the loan and the sale proceeds of the home. The NNEG can be viewed as a European put option on the mortgaged property. Li et al. ${ }^{12}$ develop a framework for pricing and managing the risks for the NNEG.

Securitisation is a new financial innovation to hedge longevity risk. Blake and Burrows $^{13}$ were the first to advocate the use of mortality-linked securities to transfer longevity risk to capital markets. The EIB/BNP longevity bond was the first securitisation instrument designed to transfer longevity risk but was not issued finally and remained theoretical. Survivor swaps, survivor futures and survivor options have been studied by both academics and practitioners. ${ }^{14}$ Although securitisation of longevity risk for annuity business and pension plans have been widely discussed and studied, securitisation of reverse mortgage is still in the early development stage. ${ }^{15}$ Wang et al. ${ }^{16}$ first illustrate a securitisation method to hedge the longevity risk inherent in RM products, ignoring interest rate risk and house price risk. They study both of a survivor bond and a survivor swap and demonstrate that securitisation can provide an efficient and economical way to hedge the longevity risk in reverse mortgages. However, Sherris and Wills ${ }^{17}$ point out that structuring of longevity risk through a special purpose vehicle (SPV) requires consideration of how best to tranche the risk in order to meet different market demands. Liao et al. ${ }^{18}$ first illustrate a collateralised debt obligation (CDO) structure to design the longevity bond with a tranche design. Wills and Sherris ${ }^{19}$ further consider the securitisation of longevity risk,

\footnotetext{
${ }^{10}$ Borrowers do not directly pay the insurance premiums. Instead, lenders make the payments to FHA on behalf of the borrowers and the cost of the insurance is added to the borrower's loan balance.

${ }^{11}$ Chen et al. (2010).

${ }^{12} \mathrm{Li}$ et al. (2010).

${ }^{13}$ Blake and Burrows (2001).

${ }^{14}$ Blake et al. (2006), Dowd et al. (2006), Macminn et al. (2006), Biffis and Blake (2009), Blake et al. (2010).

${ }^{15}$ Zhai (2000).

${ }^{16}$ Wang et al. (2008).

${ }^{17}$ Sherris and Wills (2007).

18 Liao et al. (2007).

${ }^{19}$ Wills and Sherris (2010).
} 
focusing on the structuring and pricing of a longevity bond using techniques developed for the financial markets. In addition, Biffis and Blake ${ }^{20}$ examine the impact of asymmetric information and parameter uncertainty on the securitisation and tranching of longevity exposures. Thus, structuring longevity risk is significant for a successful implementation of transferring longevity risk in capital markets. Existing literature illustrates the structuring in securitisation for longevity risk for annuity business, not for reverse mortgages. This article attempts to fill this gap by introducing the tranche design of a security for transferring the risks with reverse mortgages.

This article uses the techniques developed for credit risk in financial markets to structure the risks for reverse mortgages. The structure of the securitisation for longevity risk on RM products is similar to CDO for credit risk. Thus, we refer to the security we introduce as a collateralised reverse mortgage obligation (CRMO). The design of CRMO consists of tranching and selling the risk of the underlying portfolio of reverse mortgages. The lender of reverse mortgages, investment bank/insurance company or the guarantor, decides to buy protection from CRMO against the possible losses due to the longevity risk of the underlying borrower (homeowner) and house price risk of the home equity. The special purpose company (SPC) designs the security with the payoff depending on the uncertainty of future losses on the underlying reverse mortgages and tranche the risks to different investors. Our article differs from Wang et al's $^{16}$ in two aspects. First, Wang et al. ${ }^{16}$ propose a security for transferring longevity risk with reverse mortgages without a tranche design. Second, we consider not only longevity risk, but also house price risk for reverse mortgages, whereas Wang et al. ${ }^{16}$ focus only on longevity risk. House price risk has been found to be a major risk for reverse mortgages and cannot be ignored when pricing RM-related products. ${ }^{21}$

To illustrate the tranche design and price fair spreads for CRMO, we assume a pool of reverse mortgages. The fair spread depends on the future possible losses of the underlying pool of reverse mortgages. We model the possible losses based on the HECM programme in the U.S. because the HECM programme is considered the most popular one among the RM products in the U.S. market, which accounts for 95 per cent of the market. ${ }^{22}$ Under the HECM programme, borrowers must be at least 62 years of age. CBD mortality model ${ }^{23}$ is proposed for modelling the mortality rates for the elders. Thus, we employ the CBD model ${ }^{23}$ to capture the dynamic of future mortality for older borrowers. The properties of autocorrelation and volatility clustering for house price return dynamics are found in the literature. ${ }^{24}$ To capture these two important properties for house price return dynamics, we employ the ARMA-GARCH process to model the house price dynamics. The risk-neutral pricing framework for the CRMO is derived using conditional Esscher transform. Since mortality modelling plays an important role in pricing longevity securities, we study the impact of mortality modelling on pricing the fair spread for CRMO by comparing the fair spread using CBD model with that using the Lee-Carter (LC)

\footnotetext{
${ }^{20}$ Biffis and Blake (2010).

${ }^{21}$ Chang et al. (2010), Chen et al. (2010), Li et al. (2010).

${ }^{22} \mathrm{Ma}$ and Deng (2006), Chen et al. (2010).

${ }^{23}$ Cairns et al. (2006).

${ }^{24}$ Crawford and Fratantoni (2003), Miller and Peng (2006), Chen et al. (2010).
} 
652

model. ${ }^{25}$ In addition, the earlier HECM programme uses static mortality tables to calculate the loan value. We also investigate the effect of failing to capture the dynamics of mortality on securitisation of longevity risk for reverse mortgages.

The rest of this article is organised as follows: in the next section, we introduce the risks and the loss model for the HECM programme. Then we discuss the drivers of the future survival curve and model the future mortality using the CBD model with U.S. mortality experiences in the subsequent section, followed by our housing price return model in section after that. In the section that follows, we describe the structure and risk-neutral valuation framework for transferring the longevity and housing price risk for RM products. After we demonstrate the calculation of the fair spread and analyse the impact of longevity risk on its pricing in the penultimate section, we conclude in the last section.

\section{Modelling the risks for the HECM programme}

\section{The HECM programme}

In the U.S. market, the HECM programme, Fannie Mae's Home Keeper programme and Financial Freedom's Cash Account Advantage are the three main RM programmes. The HECM programme was authorised by the Department of HUD in the Housing and Community Development Act of 1987. Because the HECM is insured by the federal government, it is the most popular RM programme. As of May 2007, the HECM accounted for approximately 90 per cent of the market (National Reverse Mortgage Lenders Association). ${ }^{26}$

Under this programme, the borrower must be at least 62 years of age, living in a single family property that meets HUD's minimum property standard. The loan can be taken as four common repayment forms: lump sum, line of credit, tenure or term. The initial loan amount depends on the initial loan principal limit, which depends on the borrower's age, the property value and the interest rate.

From the lender's perspective, the loss occurs when the borrower lives longer than expected, or the decrease in house price, the principal advances and interest accruals may drive the loan balance above the proceeds of sale of the property. Reverse mortgages differ from traditional mortgages in the manner that the loans and accrued interests are repaid once when the borrower dies or leaves the house. Thus, unlike traditional mortgage pools, the credit risk in RM pools is not driven by potential default of the loans. Longevity risk, interest rate risk and house price risk are the major risks for reverse mortgages. If the borrower lives longer than expected, the principal advance and interest will continue to accumulate. It may cause the outstanding balance to exceed the proceeds from the sale of the property. Thus, the lenders of reverse mortgages are faced with longevity risk. A risk in interest rates can cause higher interest on the outstanding balance. Thus, it increases the risk that outstanding balance exceeds the property value. If the property value decreases, it also

\footnotetext{
${ }^{25}$ Lee and Carter (1992).

${ }^{26}$ National Reverse Mortgage Lenders Association, 2007.
} 
increases the risk that outstanding balance exceeds the proceeds from the sale of the property. This is called house price risk.

To protect the lenders from possible losses, HUD provides mortgage insurance for the HECM programme. The MIPs are paid by borrowers and include an upfront premium of 2 per cent of the adjusted property value and an annual rate of 0.5 per cent of the loan outstanding balance as long as the loan is active. Borrowers do not directly pay the insurance premiums. Instead, lenders make the payments to the Federal Housing Administration (FHA) on behalf of the borrowers, and the cost of the insurance is added to the borrower's loan balance. A lender may choose either the assignment option or the coinsurance option when originating the loan. Under the assignment option, HUD will collect all the MIP and the lender may assign the loan to HUD at the point that the loan balance equals the maximum HUD claim amount for the area. Under the coinsurance option, the lender may keep part of the MIP and forfeit the right to assign the case to HUD. To date, it indicates that all lenders have chosen the assignment option. By choosing this option, effectively, lenders are shifting the collateral risk to HUD. ${ }^{27}$ Thus, the HUD plays the role of a guarantor and has the obligation to pay the loss to the lender when the final loan balance exceeds the proceeds from the sale of a home. The risks from reverse mortgages are then shifted to the guarantor. Managing the risks associated with reverse mortgages is not only important for the lender (investment bank), but also the guarantor (usually the government). This research considers an alternative securitisation method to hedge the risks for RM products.

\section{Modelling possible losses}

Let $H_{t}$ denote the property value and $O B_{t}$ represent the loan balance at time $t$. If the loan is due at time $t$, the possible loss can be expressed as

$$
L_{t}=\max \left(O B_{t}-(1-\gamma) \times H_{t}, 0\right), \quad \text { for } t=1 \sim \omega-x,
$$

where $\omega$ is maximal survival age and $\gamma$ is the transaction cost.

The loan balance accumulates with the loan value and interest. For a lump-sum loan, the outstanding balance at time $t$ is calculated as

$$
O B_{t}=\left(L T V \times H_{0}\right) e^{c t},
$$

where $L T V$ is the lump-sum loan to value, $H_{0}$ is the initial property value and $c$ is the interest rate charged on the mortgage loan. We assume a fix interest rate in the analysis. $^{28}$

Equation (2) is a simple form to calculate the outstanding balance. In the HECM programme, the borrowers are required to pay an upfront MIP of 2 per cent of the maximum mortgage amount. In addition, borrowers pay an annual insurance premium of 0.5 per cent of the loan balance. Borrowers do not directly pay the

\footnotetext{
${ }^{27}$ Foote (2007).

${ }^{28}$ In practice, the interest may be charged based on a floating rate.
} 
insurance premiums. Thus, the outstanding balance includes the premium charges and become

$$
O B_{t}=(1+0.5 \%) \times O B_{t-1} \times e^{c}
$$

where the initial outstanding balance $\left(O B_{0}\right)$ is equal to $(2$ per cent $+L T V) \times H_{0}$.

The property value at time $t$ is calculated as

$$
H_{t}=H_{0} e^{\sum_{s=1}^{t} Y_{s}} e^{-g t}
$$

where $g$ is the rental yield and $Y_{s}$ is the house price return at time $s$.

The loan is due only if the borrower dies in that year. Thus, the present value of the expected total loss at time 0 is calculated as

$$
T L(0)=\sum_{t=1}^{\omega-x} E\left[e^{-r t}{ }_{t-1} p_{x}^{\prime} q_{x+t-1, t} L_{t}\right],
$$

where ${ }_{t-1} p^{\prime}{ }_{x}$ denotes the projected survival probability that a borrower of $x$ years will survive to age $x+t-1$, whereas $q_{x+t-1, t}$ is the projected probability that the borrower will die between age $x+t-1$ and $x+t$ during year $t$. To transfer the longevity and housing price risks for the HECM programme, we consider both mortality and housing price dynamics.

Since house price risk is also significant for pricing RM products, we consider not only the longevity risk, but also house price risk to illustrate the securitisation of the risks for reverse mortgages. The dynamics of mortality rates and house price are described below.

\section{Modelling longevity risk}

In traditional RM pricing, future mortality rates are assumed to be constant over time, which means that unanticipated mortality improvements can cause serious financial burdens or even bankruptcy for the RM provider. To securitise the longevity risk for RM products, we need a stochastic mortality model that can capture future mortality dynamics. In actuarial literature, the question of how to model mortality rates dynamically continues to represent an important issue. Various mortality models exist, including pioneering works by Lee and Carter, ${ }^{25}$ Renshaw and Haberman ${ }^{29}$ and Cairns et al. ${ }^{23}$ Renshaw and Haberman ${ }^{29}$ offer further analyses of the LC model. Cairns et $a .^{23}$ deal with mortality rates across ages, and their model offers better performance among older persons, and thus it has been adopted widely to manage longevity risk for the elderly. In addition to these discrete models, some mortality models have been built on continuous basis and are well suited to pricing longevitylinked securities under risk-adjusted probability measures, including those proposed

\footnotetext{
${ }^{29}$ Renshaw and Haberman (2003).
} 
by Milevsky and Promislow, ${ }^{30}$ Dahl, ${ }^{31}$ Biffis, ${ }^{32}$ Dahl and Møller, ${ }^{33}$ Schrager $^{34}$ and Bauer and Russ. ${ }^{35}$ Milevsky and Promislow ${ }^{29}$ were the first to propose a stochastic hazard rate or force of mortality. Dahl ${ }^{31}$ presents a general stochastic model for the mortality intensity. A specification of the model with an affine term structure is employed in Dahl and $\mathrm{M} \varnothing l$ ler ${ }^{33}$ and Schrager. ${ }^{34}$ Since reverse mortgage is sold to old-age persons above 62 years in the HECM programme, to better capture the mortality rates for old-age persons, we employ the CBD stochastic mortality to model longevity risk for RM products, though we also investigate the impact of mortality models on pricing by comparing its results with results obtained with the well-known LC model as well as the static mortality table.

\section{The CBD model}

We first give a brief overview of the CBD model. Cairns et al. ${ }^{23}$ suggest a two-factor model for modelling initial mortality rates instead of a central mortality rate. The mortality rate for a person aged $x$ years in year $t$, denoted as $q_{x, t}$, is modelled as

$$
\text { logit } q_{x, t}=\kappa_{t}^{1}+\kappa_{t}^{2}(x-\bar{x}),
$$

where parameter $\kappa_{t}^{1}$ represents the marginal effect with times on mortality rates and parameter $\kappa_{t}^{2}$ portrays the old-age effect on mortality rates and $\bar{x}$ is the mean age. Once the parameters are estimated, we are able to forecast age-specific mortality rates by modelling $\kappa_{t}^{1}$ and $\kappa_{t}^{2}$.

\section{Parameter estimates and goodness of fits}

We estimate the parameters in the CBD model by fitting historical U.S. mortality data from 1950-2006 with the human mortality database (HMD). ${ }^{36}$ We estimate the parameters in Eq. (6) using the maximum likelihood method. The fitting accuracy of the CBD model for men and women are shown in Table 1. We report the log-likelihood (LL), Akaike information criteria (AIC) and Bayesian information criteria (BIC). The Lower value of the AIC or BIC indicates the preferred model. On the basis of the mortality data for old-age persons, we find that the CBD model performs better than the LC model. In addition, men between ages 60-69 and women between ages 70-79 give the lowest values of AIC and BIC. The estimated parameters of $\kappa_{t}^{1}$ and $\kappa_{t}^{2}$ for men and women are depicted in Figures 1 and 2. $\kappa_{t}^{1}$ shows a down trend and $\kappa_{t}^{2}$ shows a upward trend, but falls in recent years. This may explain the fact that the recent mortality improvement for old-age persons is more obvious due to the progress in medical services.

\footnotetext{
${ }^{30}$ Milevsky and Promislow (2001).

${ }^{31}$ Dahl (2004).

32 Biffis (2005).

33 Dahl and Møller (2005).

${ }^{34}$ Schrager (2006).

${ }^{35}$ Bauer and Russ (2006).

${ }^{36}$ HMD (2010).
} 
Table 1 The fitting accuracy of the CBD and LC models for men and women

\begin{tabular}{|c|c|c|c|c|c|}
\hline & All & $60 \sim 69$ & $70 \sim 79$ & $80 \sim 89$ & $90+$ \\
\hline \multicolumn{6}{|l|}{$C B D$} \\
\hline \multicolumn{6}{|l|}{ Women } \\
\hline LL & $-26,943.2$ & -4004.6 & -3749.0 & -8158.0 & $-11,031.6$ \\
\hline AIC & $54,114.3$ & 8237.1 & 7726.1 & $16,544.0$ & $22,291.2$ \\
\hline BIC & $54,767.8$ & 8890.5 & 8379.5 & $17,197.4$ & $22,944.6$ \\
\hline \multicolumn{6}{|l|}{ Men } \\
\hline LL & $-23,142.4$ & -3238.2 & -3527.9 & -8852.2 & -7524.2 \\
\hline AIC & $46,512.9$ & 6704.4 & 7283.9 & $17,932.3$ & $15,276.3$ \\
\hline $\mathrm{BIC}$ & $47,166.3$ & 7357.8 & 7937.3 & $18,585.7$ & $15,929.8$ \\
\hline \multicolumn{6}{|l|}{$L C$} \\
\hline \multicolumn{6}{|l|}{ Women } \\
\hline LL & $-30,667.0$ & -4393.5 & -5024.6 & -8698.0 & $-12,550.9$ \\
\hline AIC & $61,642.0$ & 8970.9 & $10,233.3$ & $17,580.1$ & $25,289.7$ \\
\hline BIC & $62,568.7$ & 9394.7 & $10,657.1$ & $18,003.9$ & $25,731.7$ \\
\hline \multicolumn{6}{|l|}{ Men } \\
\hline LL & $-28,448.9$ & -4235.7 & -5415.4 & -9600.9 & -9197.0 \\
\hline AIC & $57,205.8$ & 8655.3 & $11,014.8$ & $19,385.8$ & $18,581.9$ \\
\hline $\mathrm{BIC}$ & $58,132.6$ & 9079.1 & $11,438.6$ & $19,809.6$ & $19,023.9$ \\
\hline
\end{tabular}

$\mathrm{AIC}=-2 / \mathrm{T} \ln ($ likelihood $)+2 / \mathrm{T} \times($ number of parameters) (Akaike, 1973).

$\mathrm{BIC}=-2 / \mathrm{T} \ln ($ likelihood $)+(($ number of parameters $) \times \ln (\mathrm{T})) / \mathrm{T}$.
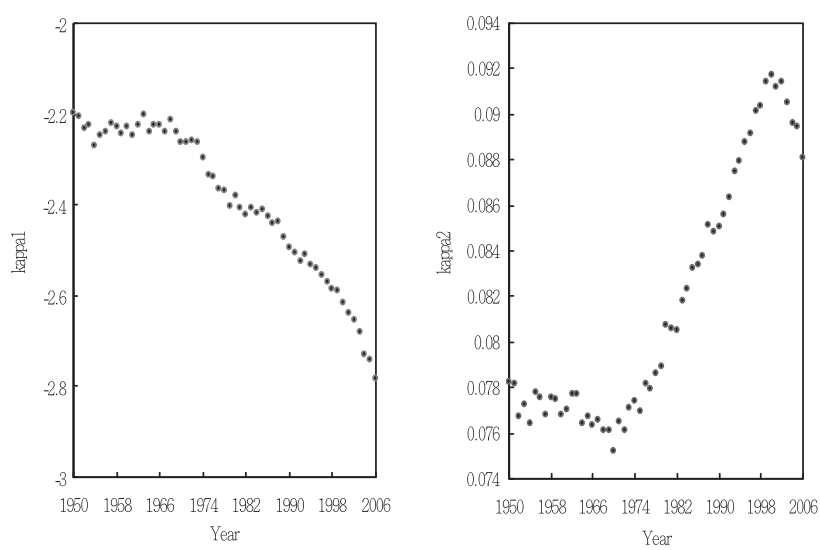

Figure 1. Estimated values of $\kappa_{t}^{1}$ and $\kappa_{t}^{2}$ of men, 1950-2006.

\section{Project future mortality rates}

To project future mortality rates, we follow Cairns et $a .^{22}$ to forecast $\kappa_{t}^{1}$ and $\kappa_{t}^{2}$. Let $\kappa_{t}=\left(\kappa_{t}^{1}, \kappa_{t}^{2}\right)^{\prime}$. We model $\kappa_{t}$ as a two-dimensional random walk with drift. Specifically,

$$
\kappa_{t+1}=\kappa_{t}+\mu+C Z(t+1),
$$



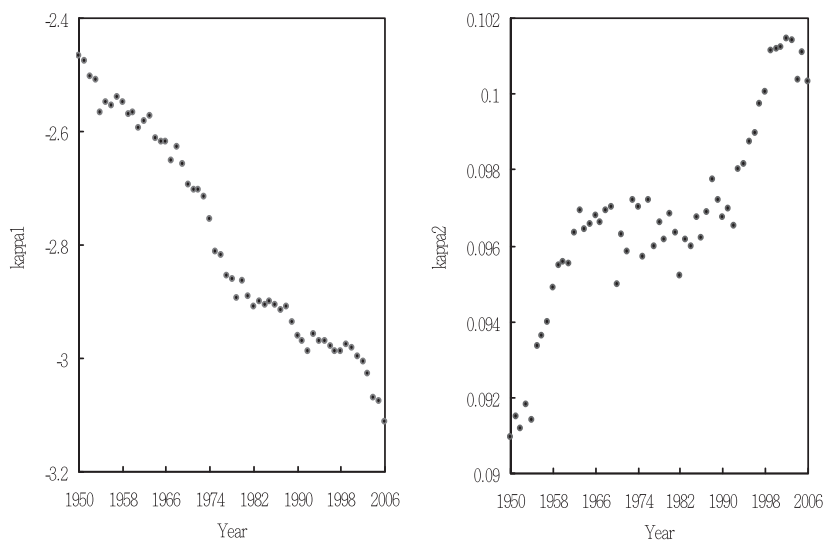

Figure 2. Estimated values of $\kappa_{t}^{1}$ and $\kappa_{t}^{2}$ of women, 1950-2006.

where $\mu$ is a constant $2 \times 1$ vector, $C$ is a constant $2 \times 2$ upper triangular matrix and $Z(t)$ is a two-dimensional standard normal random variable. On the basis of the mortality data from 1950 to 2006, we find that $\mu=\left[\begin{array}{l}\mu_{1}=-0.01040 \\ \mu_{2}=0.00018\end{array}\right]$ and $C=$ $\left[\begin{array}{cc}0.01922, & 0 \\ 0.00036, & 0.00065\end{array}\right]$ for men; $\mu=\left[\begin{array}{l}\mu_{1}=-0.01156 \\ \mu_{2}=0.00017\end{array}\right]$ and $C=\left[\begin{array}{cc}0.01965 & 0 \\ 0.00054, & 0.00053\end{array}\right]$

for women. We can use these parameters to project $\kappa_{t}^{1}$ and $\kappa_{t}^{2}$ and obtain projected mortality rates.

Mortality modelling plays an important role in longevity securitisation. Figure 3 shows the simulated survival probability for a man aged 62 years old. For a comparison, we also examine the longevity risk modelled by the $\mathrm{LC}$ model ${ }^{25}$ to investigate the effect of model risk on securitisation for reverse mortgages. The LC model is emerging as a benchmark for mortality forecasts. However, its suitability for pricing longevity-linked securities is restricted, due to limitations in incorporating a risk adjustment into the mortality distribution. ${ }^{19}$ Thus, we only employ the LC model for a comparison purpose.

In addition, the reverse mortgage has often been priced using static mortality table. To understand the distinction among the CBD, LC mortality models and static mortality rates, ${ }^{37}$ we compare the simulated survival probability for a man aged 62 years separately in Figure 3, which shows that the survival probability projected by the CBD model is greater than that offered by the LC model. Since the static mortality rates ignoring the mortality improvement, the projected survival probability is quite underestimated.

${ }^{37}$ We use the mortality rates in year 2006 as the static mortality rates. 


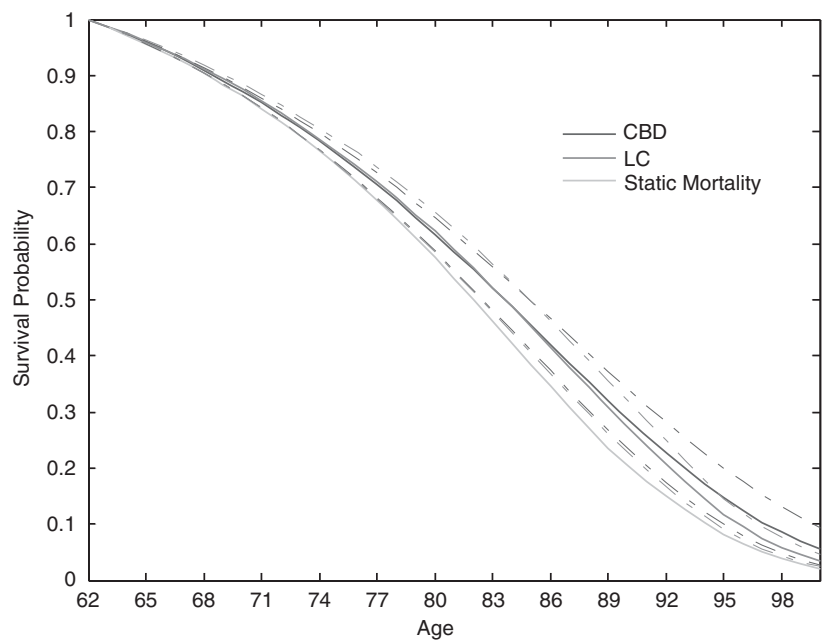

Figure 3. Simulated survival probability for American men.

\section{Modelling housing price dynamics}

\section{The house price data}

The properties of autocorrelation effect and volatility clustering have been investigated with house price return dynamics. Specifically, Li et al. ${ }^{12}$ find three important properties for these dynamics in their U.K. study: autocorrelation, volatility clustering and leverage effects. Using nationwide house price index (HPI) in the United States though, Chen et al. ${ }^{11}$ find no leverage effect. In our investigation of the HECM programme, we thus focus on autocorrelation and volatility clustering to model the housing price return dynamic.

Chen et al. ${ }^{11}$ deal with the HECM programme and choose the nationwide HPI to model the house price dynamics. We use the same house price data and extend the data period from the first quarter of 1975 to the first quarter of 2010 (see Figure 4). Let $Y_{t}$ denote the log-return for the HPI, defined as $Y_{t}=\log \left(H_{t} / H_{t-1}\right)$. The empirical HPI data in Figure 4 indicates that the log-return of HPI is not stationary, ${ }^{38}$ whereas the first difference of the log-return $\left(D Y_{t}\right)$ is. Thus, we can model the housing price return based on the first difference of log-return, calculated as $Y_{t}-Y_{t-1}$.

\section{ARMA-GARCH process}

We apply time-series analysis to investigate housing price return data and thus develop the $\operatorname{ARMA}(s, m)-\operatorname{GARCH}(p, q)$ model. Two specifications are required in order to

\footnotetext{
${ }^{38}$ Both the ADF statistic and the PP statistic in CSXR are greater than the critical values at a 5 per cent significance level.
} 

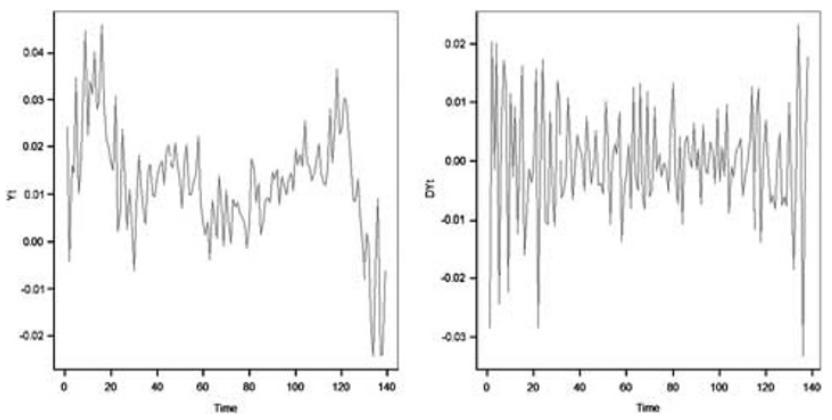

Figure 4. Log-return of HPI from 1975/Q1 to 2010/Q1.

develop such a model: the conditional mean and the conditional variance. The conditional mean model ARMA $(s, m)$ can be expressed as

$$
D Y_{t}=c+\sum_{i=1}^{s} \tau_{i} D Y_{t-1}+\sum_{j=1}^{m} \zeta_{j} \varepsilon_{t-j}+\varepsilon_{t},
$$

where $s$ is the order of the autocorrelation terms, $m$ is the order of the moving average terms, $\tau_{i}$ is the $i^{\text {th }}$-order autocorrelation coefficient, $\zeta_{j}$ is the $j^{\text {th }}$-order moving average coefficient and $\varepsilon_{t}$ is the $i^{\text {th }}$ Gaussian innovation. Let $h_{t}$ denote the conditional variance of the innovations, given an information set of $\Phi_{t-1}$. The conditional variance model $\operatorname{GARCH}(p, q)$ for the innovations then can be written as

$$
h_{t}=w+\sum_{i=1}^{q} \alpha_{i} \varepsilon_{t-i}^{2}+\sum_{j=1}^{p} \beta_{j} h_{t-j},
$$

where $p$ is the order of the GARCH terms, $q$ is the order of the ARCH term, $\alpha_{i}$ is the $i^{\text {th }}$-order ARCH coefficient and $\beta_{j}$ is the $j^{\text {th }}$-order GARCH coefficient.

\section{Parameter estimates}

From our empirical data, we find that the $\operatorname{ARMA}(2,0)-\operatorname{GARCH}(1,1)$ process offers the best fit to the HPI data. ${ }^{39}$ The parameter estimates appear in Table 2 .

\section{The structure of securitisation for reverse mortgages and valuation of CRMO}

The structure of securitisation for reverse mortgages

We propose a tranche security, the structure of which is similar to CDO. A CDO is an asset-backed securitisation where the underlying portfolio comprises a portfolio (called a Collateralised Bond Obligation, CBO) or loans (called a Collateralised Loan Obligation,

${ }^{39}$ Chen et al. (2010) also find that ARMA(2,0)-GARCH(1,1) gives the best fit to the data for a period from $1975 /$ Q1 to $2009 /$ Q1. 
The Geneva Papers on Risk and Insurance-Issues and Practice

660

Table 2 Parameter estimates for the $\operatorname{ARMA}(2,0)-\operatorname{GARCH}(1,1)$ process

\begin{tabular}{lcccc}
\hline Parameters & Estimate & Std. Error & $t$-value & $\operatorname{Pr}(>|t|)$ \\
\hline$\tau_{1}$ & -0.3830 & 0.0795 & -4.8158 & $1.47 \mathrm{E}-06$ \\
$\tau_{2}$ & -0.4236 & 0.0820 & -5.1638 & $2.42 \mathrm{E}-07$ \\
$\alpha_{0}$ & 0.0000 & $2.47 \mathrm{E}-06$ & 1.3988 & 0.1619 \\
$\alpha_{1}$ & 0.1045 & 0.0524 & 1.9965 & 0.0459 \\
$\beta_{1}$ & 0.8288 & 0.0768 & 10.7853 & $0.00 \mathrm{E}+00$ \\
\hline
\end{tabular}

CLO) or possibly a mixture of securities and loans. The first CDO was created in 1987 by the famous Drexel Burnham Lambert. A CDO consists of tranching and selling the credit risk of the underlying portfolio. We design a securitisation where the underlying portfolio is a pool of RM products. We call it CRMO in this research.

The structure of CRMO is described in Figure 5. The securitisation process in general involves three parts: the protection seller, the protection buyer and the investor. The borrower collects the lump sum from the reverse mortgages lender. To protect the lender from the risk of not being able to fully recover the accumulated loan amount, the lender enters into an insurance contract with the SPC. The protection buyer (the lender), investment bank or guarantor, pays the premiums $(P)$ to the protection seller, special purpose vehicle (SPV). If the loss occurs, the SPC will pay the lender a certain amount of benefit. The SPV issues three tranches of the CRMO to investors with different degree of risk preferences. The total face amount of bonds issuing to investor is equal to $F$. SPV invests the premium $(P)$ and the proceeds from the sale of bonds $(F)$ in default-free floating bonds with coupon rate $\left(C_{t}\right)$. If the loss $\left(L_{t}\right)$ on the underlying RM product occurs, the tranche investor will receive the residual nominal value of contract $\left(F-L_{t}\right)$. Thus, the investor forfeits a fraction of their prescribed face amount to the issuer, as compensation for the issuer's incurred losses on RM products. The investor will bear the future uncertainty of loss and will need to be compensated. The compensation return is called spread. In this research, we investigate the fair spreads for different tranche investors. The structure of CRMO in this research is different from the security for RM in the study by Wang et al., ${ }^{16}$ where the loss is compensated by the coupon payment paid to the investor each year.

The SPV distributes the sales of bonds to each tranche according to the tranching proportion ( $S$ per cent, $M$ per cent, $E$ per cent), to senior, mezzanine and equity tranche investors, respectively. The corresponding face amounts and fair spread for these three tranches are denoted $\left(F^{S}, F^{M}, F^{E}\right)$ and $\left(r_{S}\right.$ per cent, $r_{M}$ per cent, $r_{E}$ per cent). Different tranche investors receive different spreads. At time $t$, when a loss occurs $\left(L_{t}\right)$, the equity tranche first absorbs the loss, and the amount decreases accordingly. If the loss is larger than the residual amount in the equity tranche, the mezzanine tranche becomes responsible; the senior tranche is the last to absorb the loss. The future residual face amount in all three tranches at time $t+1$ can be expressed as

$$
F_{t+1}^{E}= \begin{cases}F_{t}^{E} & \text { if } L_{t}=0 \\ F_{t}^{E}-L_{t} & \text { if } 0<L_{t} \leqslant F_{t}^{E} \\ 0 & \text { if } L_{t}>F_{t}^{E}\end{cases}
$$




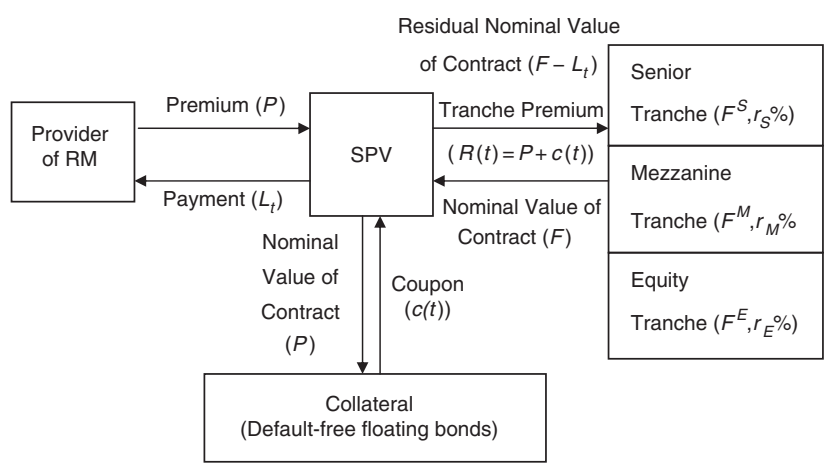

Figure 5. The structure of CRMO.

$$
\begin{gathered}
F_{t+1}^{M}= \begin{cases}F_{t}^{M} & \text { if } L_{t} \leqslant F_{t}^{E} \\
F_{t}^{M}-L_{t} & \text { if } F_{t}^{E}<L_{t} \leqslant F_{t}^{M} \\
0 & \text { if } L_{t}>F_{t}^{M},\end{cases} \\
F_{t+1}^{S}= \begin{cases}F_{t}^{S} & \text { if } L_{t} \leqslant F_{t}^{M} \\
F_{t}^{S}-L_{t} & \text { if } F_{t}^{M}<L_{t} \leqslant F_{t}^{S} \\
0 & \text { if } L_{t}>F_{t}^{S} .\end{cases}
\end{gathered}
$$

From the investor's point of view, because the equity tranche first absorbs the loss, it is the most risky, compared with the mezzanine or senior tranches. The SPV can decide the tranche proportion to match market demands according to the percentage cumulative loss on the portfolio of RM policies. In a CDO, the percentage cumulative loss is the percentage of the portfolio that has defaulted by a certain time. However, in longevity securitisation or the proposed CRMO, the number alive can exceed expectations consistently over a number of years. Thus, a difficulty in structuring CRMO or longevity securitisation is defining the percentage cumulative loss on the portfolio. Liao et al. ${ }^{18}$ overcome this by defining the percentage cumulative loss based on the face value of the bond issued. They determine optimal tranche weights to match hypothetical market demands for expected loss exposures. Wills and Sherris ${ }^{19}$ also apply Liao et al. ${ }^{18}$ to structuring a longevity bond. In this research, we follow Liao et $a l .{ }^{18}$ to calculate the percentage cumulative loss on the portfolio of RM policies based on the tranche proportion.

\section{Valuation of CRMO}

We propose a risk-neutral valuation framework to find the fair spread for different tranche investors. On the basis of the underlying portfolio of RM policies, the total 
losses are modelled according to Eq. (1). Assume the loss occurs at the middle year. At time 0 , the present value of the expected total loss to be absorbed by equity tranche investors is calculated as

$$
L_{E}(0)=\sum_{t=1}^{T} e^{-r(t-0.5)}\left(E_{Q}\left[F_{t-1}^{E}-F_{t}^{E}\right]\right),
$$

where $r$ is the risk-free rate, $\left(F_{t-1}^{E}-F_{t}^{E}\right)$ denotes the actual loss at time $t$ absorbed by the equity tranche and $E_{Q}[]$ represents the expectation under a risk-neutral measure.

Therefore, we can express the present value of the expected total compensation received by the equity tranche investor as

$$
P_{E}(0)=\sum_{t=1}^{T} e^{-r t} E_{Q}\left[r_{E} \times\left(F_{t-1}^{E}+F_{t}^{E} / 2\right)\right] .
$$

In turn, we obtain the fair spread $\left(r_{E}\right)$ for the equity tranche investor by setting

$$
P_{E}(0)=L_{E}(0)
$$

Thus, the expected total losses absorbed and the expected total compensation received by the equity tranche investor is the same. The valuation formula applies to the mezzanine and senior tranches too. In addition, the present value of expected total losses in Eq. (2) equals total losses absorbed in different tranches, or

$$
T L(0)=L_{E}(0)+L_{M}(0)+L_{S}(0)
$$

We carry out simulations to find the fair spreads for different tranche investors based on the risk-neutral valuation framework. Thus, we need to find the house price dynamics and mortality rate dynamics under the risk-neutral measure separately. For mortality rates, we follow Cairns et $a l .^{23}$ to specify the dynamics under a risk-adjusted pricing measure $Q$. The measure $Q$ is also commonly referred to as the risk-neutral measure. Under the risk-adjusted measure $Q(\lambda)$, Eq. (7) is adjusted as

$$
\begin{aligned}
\kappa_{t+1} & =\kappa_{t}+\mu+C(\tilde{Z}(t+1)-\lambda) \\
& =\kappa_{t}+\tilde{\mu}+C \tilde{Z}(t+1)-\lambda
\end{aligned}
$$

where $\tilde{\mu}=\mu-C \lambda$.

Regarding the house price dynamics, Eqs. (8) and (9) represent the real-world house price dynamics. To value the security, we need to obtain the house price dynamics under risk-neutral measure. To achieve this goal, we employ the conditional Esscher transform technique developed by Bühlmann et al. ${ }^{40}$ The Esscher transform has been widely applied to price financial and insurance securities in an incomplete

${ }^{40}$ Bühlmann et al. (1996). 
market. ${ }^{41}$ We utilise the same technique of conditional Esscher transform to price CRMO in this research. The first difference of log-house price return $\left(D Y_{t}\right)$ based on the $\operatorname{ARMA}(s, m)-\operatorname{GARCH}(p, q)$ model under a risk-neutral measure $\mathbf{Q}$ becomes

$$
\begin{aligned}
D Y_{t}^{Q} & =r-g-\frac{h_{t}^{Q}}{2} \\
h_{t}^{Q} & =w+\sum_{i=1}^{q} \alpha_{i}\left(\xi_{t-i}-\eta \sqrt{h_{t-i}^{Q}}\right)^{2}+\sum_{j=1}^{p} \beta_{j} h_{t-j}^{Q}
\end{aligned}
$$

The derivation of Eq. (15) based on conditional Esscher transform is described in the Appendix. The reader can also refer Chen et al. ${ }^{11}$ for details.

\section{Numerical illustration}

\section{Policy setting for reverse mortgages}

To illustrate the calculation of the fair spread for the tranching security of RM products, we assume a portfolio of 1,000 identical policies issued to borrowers aged 62 years, with an initial property value of US $\$ 300,000$ and a lump-sum payment loan. The total loan value is US\$180,000,000. Assume the loan provider wants to transfer all risk. The SPV issues a bond with a total face amount of US\$180,000,000 for 20 years. We provide examples of tranche levels and the distribution of the face amount to each tranche in Table 3. Then on the basis of the tranche level, we can investigate the fair spread for investors in different tranches.

On the basis of the tranche level, we investigate the fair spread for different tranche investors.

Following the policy setting of RM products in Chen et al., ${ }^{11}$ we consider the transaction cost of selling the house $(\kappa)$ and rental yield $(g)$ in our numerical analysis. Assume $\kappa=5$ per cent and $g=2$ per cent. The interest rate charged on the loan $(c)$ is assumed to be 4.6 per cent. The mortality model and the house price model used to model the possible losses are presented in the sections "Modelling longevity risk" and "Modelling housing price dynamics". The risk-free rate is assumed to be constant and we use 3.84 per cent. The risk adjust premium $(\lambda)$ for calculate the risk-neutral mortality rate is assumed to be -0.1 . The sensitivity on the risk adjust premium is investigated. We carry out 100,000 Monte Carlo Simulations to calculate the numerical results.

\section{Shortfalls analysis for issuing RM products}

We first analyse the shortfalls for the provider when issuing a portfolio RM Products. On the basis of different loan to values, Table 4 presents the shortfalls in terms of

\footnotetext{
${ }^{41}$ Gerber and Shiu (1994), Siu et al. (2004), Chen et al. (2010), Li et al. (2010).
} 
Table 3 Illustration of tranche levels

\begin{tabular}{lrr}
\hline & Tranching & Froportion (\%) amount \\
\hline Equity tranche & 5 & 900,000 \\
Mezzanine tranche & 10 & $1,800,000$ \\
Senior tranche & 85 & $15,300,000$ \\
Total & 100 & $180,000,000$ \\
\hline
\end{tabular}

Table 4 Shortfall for a portfolio of RM policies

\begin{tabular}{|c|c|c|c|c|c|c|c|c|c|c|}
\hline$L T V(\%)$ & Gender & $\begin{array}{c}\text { Prob. of } \\
\text { no Loss } \\
\left(\begin{array}{c}\text { Loss }=0) \\
(\%)\end{array}\right.\end{array}$ & $\operatorname{Max}$ & Mean & $\begin{array}{l}\text { VaR } \\
90 \%\end{array}$ & $\begin{array}{l}\text { VaR } \\
95 \%\end{array}$ & $\begin{array}{l}\text { VaR } \\
99 \%\end{array}$ & $\begin{array}{l}C T E \\
90 \%\end{array}$ & $\begin{array}{l}C T E \\
95 \%\end{array}$ & $\begin{array}{l}C T E \\
99 \%\end{array}$ \\
\hline \multirow[t]{2}{*}{50} & Male & 6.5640 & 81,460 & 40,212 & 60,396 & 63,125 & 67,630 & 63,765 & 65,858 & 69,492 \\
\hline & Female & 6.5640 & 61,520 & 31,113 & 46,444 & 48,504 & 51,956 & 49,006 & 50,594 & 53,464 \\
\hline \multirow[t]{2}{*}{60} & Male & 3.8640 & 98,831 & 52,988 & 75,035 & 78,038 & 82,976 & 78,736 & 81,038 & 85,099 \\
\hline & Female & 3.8640 & 74,323 & 40,698 & 57,394 & 59,691 & 63,524 & 60,260 & 62,035 & 65,254 \\
\hline \multirow[t]{2}{*}{70} & Male & 1.7860 & 116,622 & 66,656 & 90,127 & 93,317 & 98,716 & 94,115 & 96,617 & 101,104 \\
\hline & Female & 1.7860 & 87,335 & 50,868 & 68,679 & 71,170 & 75,380 & 71,776 & 73,733 & 77,292 \\
\hline \multirow[t]{2}{*}{80} & Male & 0.4660 & 134,548 & 81,032 & 105,574 & 108,969 & 114,775 & 109,835 & 112,526 & 117,414 \\
\hline & Female & 0.4660 & 100,471 & 61,492 & 80,161 & 82,831 & 87,441 & 83,509 & 85,640 & 89,537 \\
\hline \multirow[t]{2}{*}{90} & Male & 0.0080 & 152,734 & 95,988 & 121,383 & 124,982 & 131,224 & 125,935 & 128,818 & 134,095 \\
\hline & Female & 0.0080 & 113,712 & 72,478 & 91,874 & 94,719 & 99,749 & 95,478 & 97,778 & 102,018 \\
\hline
\end{tabular}

Value-at-Risk (VaR) and Conditional Tail Expectation (CTE). As expected, the higher the LTV, the higher the shortfalls. For the LTV equal to 90 per cent, the probability of no loss occurring is less than 1 per cent ( 0.008 per cent actually) and CTE (90 per cent) is US\$125,935 for men and US\$95,478 for women. Comparing the results with that of LTV equal to 50 per cent, the probability of no loss occurring is around 6.56 per cent and, CTE (90 per cent) is US\$63,765 for men and US\$49,006 for women. The shortfall is much smaller. Thus, the LTV is very critical to the risk involved in issuing RM policy. Transferring the risk for RM provider is necessary especially for higher LTV. Thus, the issuer of CRMO shall choose LTV based on the lender's policy condition.

\section{Analysis of fair spreads}

The fair spreads of CRMO for different tranches are presented in Table 5. For an illustration purpose, we calculate the fair spreads for both male and female borrowers and different LTV of 50 per cent, 60 per cent, 70 per cent, 80 per cent and 90 per cent. On the basis of the LTV of 60 per cent, the fair spread for equity tranche is 8.517 per cent, for mezzanine is 4.7445 per cent and for senior is 1.5507 per cent for male borrowers. Different tranche investors bear different degrees of risk. Since the equity tranche investor absorbs the loss first, before another tranche investor, the fair spread in equity tranche is much higher than other tranches. The fair spreads for the three 
Table 5 Fair spreads for different tranches of CRMO $(\lambda=-1 \%)$

\begin{tabular}{|c|c|c|c|c|}
\hline$L T V(\%)$ & $R M$ borrower & $\begin{array}{c}\text { Equity }(\%) \\
5 \%\end{array}$ & $\begin{array}{c}\text { Mezzanine (\%) } \\
10 \%\end{array}$ & $\begin{array}{c}\text { Senior }(\%) \\
85 \%\end{array}$ \\
\hline \multirow[t]{2}{*}{50} & Male & 8.3925 & 4.6064 & 0.4696 \\
\hline & Female & 7.3520 & 3.9161 & 0.2481 \\
\hline \multirow[t]{2}{*}{60} & Male & 10.3887 & 5.5232 & 0.7785 \\
\hline & Female & 8.8983 & 4.6618 & 0.4573 \\
\hline \multirow[t]{2}{*}{70} & Male & 12.7720 & 6.4592 & 1.1354 \\
\hline & Female & 10.6531 & 5.3730 & 0.7000 \\
\hline \multirow[t]{2}{*}{80} & Male & 15.6725 & 7.4464 & 1.5361 \\
\hline & Female & 12.6724 & 6.0820 & 0.9701 \\
\hline \multirow[t]{2}{*}{90} & Male & 19.3666 & 8.5092 & 1.9802 \\
\hline & Female & 15.0652 & 6.8096 & 1.2643 \\
\hline
\end{tabular}

Table 6 The effect of risk premium on fair spreads $(L T V=60 \%)$

\begin{tabular}{llccc}
\hline Risk premium & RM borrower & $\begin{array}{c}\text { Equity }(\%) \\
5 \%\end{array}$ & $\begin{array}{c}\text { Mezzanine }(\%) \\
10 \%\end{array}$ & $\begin{array}{c}\text { Senior }(\%) \\
85 \%\end{array}$ \\
\hline$\lambda=0.0$ & & 10.4089 & 5.5525 & 0.8078 \\
$\lambda=-0.1$ & Male & 8.9203 & 4.6951 & 0.4815 \\
& Female & 10.3887 & 5.5232 & 0.7785 \\
$\lambda=-0.2$ & Male & 8.8983 & 4.6618 & 0.4573 \\
& Female & 10.3683 & 5.4936 & 0.7497 \\
$\lambda=-0.3$ & Male & 8.8761 & 4.6280 & 0.4337 \\
& Female & 10.3478 & 5.4637 & 0.7216 \\
& Male & 8.8537 & 4.5936 & 0.4108 \\
\hline
\end{tabular}

tranches are lower for female borrowers. This is because the life expectancy for women is longer.

We further compare the fair spreads for the underlying RM portfolio with different LTV. As expected, the higher the LTV, the higher the fair spread is. Since the higher LTV may result in higher loss, the investor needs to bear more risk and requires more compensation. In addition, the change in spreads is more significant for the equity tranche investors and less significant for senior tranche investors. For the LTV of 50-90 per cent, the fair spread changes from 8.3925 per cent to 19.3666 per cent for equity tranche investors (men), more than 11 per cent difference; but from 0.4696 per cent to 1.9802 per cent for senior tranche investors, less than 1.5 per cent difference.

In Table 5, the fair spreads are calculated assuming the risk premium is -0.1 . We further investigate the risk premium assumption on the calculation of fair spread. Table 6 presents the fair spread based on risk premium assumption of $0,-0.1$, -0.2 and -0.3 . As expected, the lower the risk premium in pricing, the lower the fair spread is.

Table 7 analyses the effect of tranching level on fair spreads based on risk premium assumption of -0.1 . The more proportion in equity tranche is, the lower the fair spreads for the mezzanine and senior tranches. 
Table 7 The effect of tranche level on fair spread $(L T V=60 \%, \lambda=-1 \%)$

\begin{tabular}{lccc}
\hline$R M$ borrower & \multicolumn{3}{c}{ Tranche level } \\
\cline { 2 - 4 } & Equity $(\%)$ & Mezzanine (\%) & Senior $(\%)$ \\
\hline & $5 \%$ & $10 \%$ & $85 \%$ \\
\cline { 2 - 4 } Male & 10.3887 & 5.5232 & 0.7785 \\
Female & 8.8983 & 4.6618 & 0.4573 \\
& $10 \%$ & $10 \%$ & $80 \%$ \\
Male & 7.9754 & 4.4446 & 0.6056 \\
Female & 6.8018 & 3.7049 & 0.2954 \\
& $5 \%$ & $15 \%$ & $80 \%$ \\
Male & 10.3887 & 4.9789 & 0.6056 \\
Female & 8.8983 & 4.1794 & 0.2954 \\
\hline
\end{tabular}

According to Table 7, we further investigate the expected cumulative tranche loss ${ }^{42}$ according to different tranche level in Figures 6, 7 and 8. The cumulative tranche loss occurs first in equity tranche. On the basis of the tranche level of ( 5 per cent, 10 per cent, 85 per cent), the expected loss occurs after three years in equity tranche. In addition, by comparing the Figures 6, 7 and 8 , we find that as the tranching proportion in equity tranche increases; it delays the time that the loss occurs in mezzanine and senior tranche.

\section{The impact of mortality assumption on fair spreads}

Securitisation longevity risk for annuity business has been widely discussed. The discussion of longevity risk to reverse mortgages is still under development. The earlier HECM program uses static mortality tables to calculate the loan value. To investigate the effect of failing to capture the dynamics of mortality on securitisation of longevity risk for reverse mortgages, Table 8 presents the result using the static mortality table. ${ }^{43}$ Comparing the results with Table 5, the fair spread increases in each tranche. From the SPV point of view, ignoring mortality dynamic will overestimate the fair spread.

Finally, we investigate the fair spread based on different mortality models. We employ the LC model to calculate the fair spread and compare the results with the CBD model in Table 9. In most of the cases, the fair spread based on the LC model is lower. This is because the projected life expectancy using the CBD model is a little bit longer than that using the LC model.

\footnotetext{
${ }^{42}$ We follow Liao et al. (2007) and Wills and Sherris (2010) to define the expected cumulative tranche loss. The reader can refer to their paper for details.

${ }^{43}$ On the basis of HMD, we use the mortality experience in year 2006 as the static mortality table.
} 

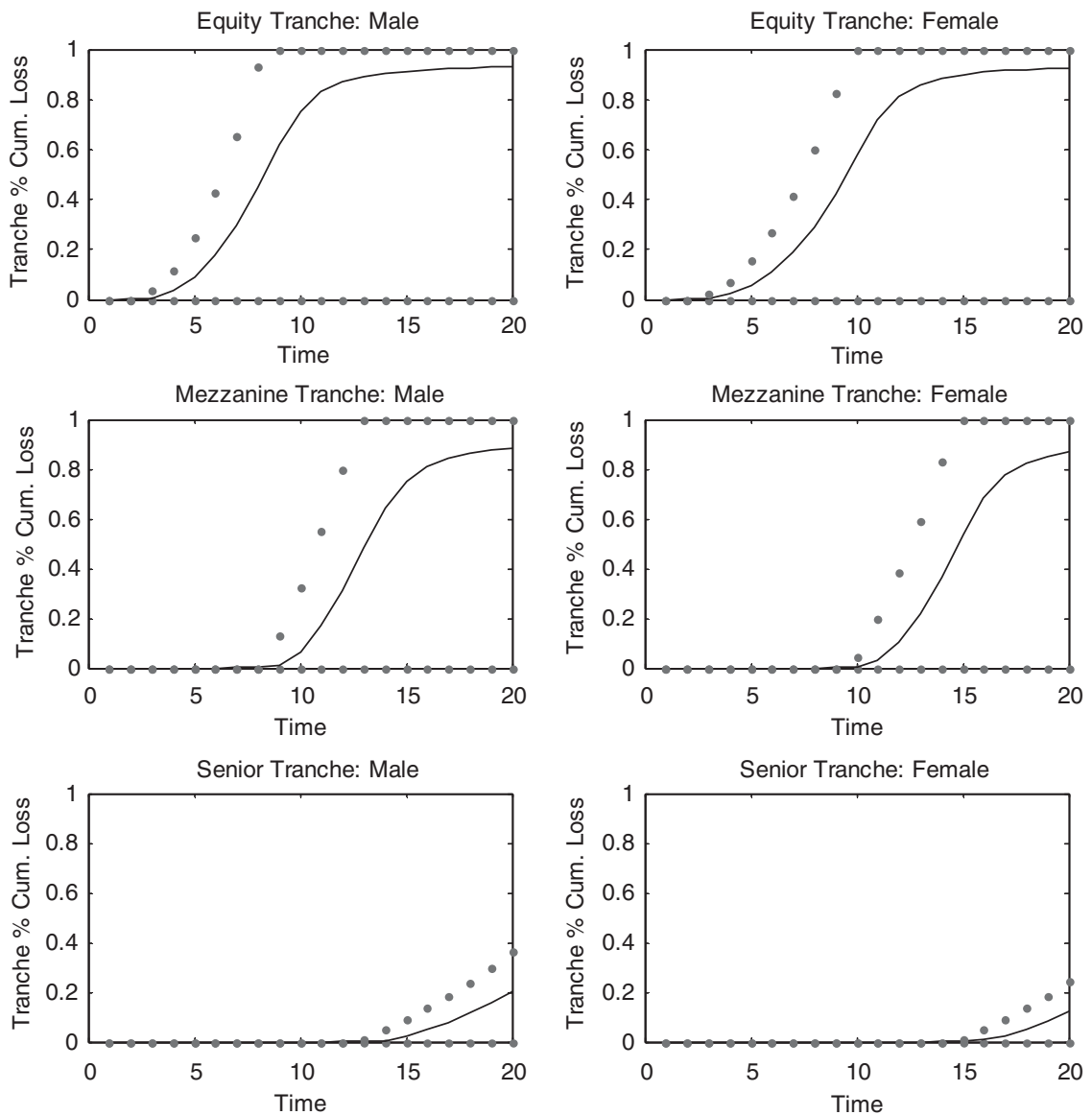

Figure 6. Expected cumulative tranche loss (solid), with 95 per cent bounds (dotted): 5 per cent, 10 per cent, 85 per cent Tranche Level; $L T V=60$ per cent, $\lambda=-1$ per cent.

\section{Conclusion}

In recent years, reverse mortgages have been getting more popular in many countries. To transfer the risk inherent to RM products, we propose a securitisation method. The proposed securitisation structure differs from existing literature by introducing the tranche longevity and house price risks for reverse mortgages. The structure of securitisation for reverse mortgages is similar to that for CDO. Different to price $\mathrm{CDO}$, we model the dynamics of future mortality and house price instead of default rate. Thus, we model the house price index using the ARMA-GARCH process. To deal with longevity risk for elders, we use the $\mathrm{CBD}$ model ${ }^{23}$ to project future mortality. We propose a risk-neutral valuation framework and employ the conditional Esscher transform to price the fair spreads for different tranche investors. The problems of using static mortality table and model risk on pricing fair spread are investigated numerically. 

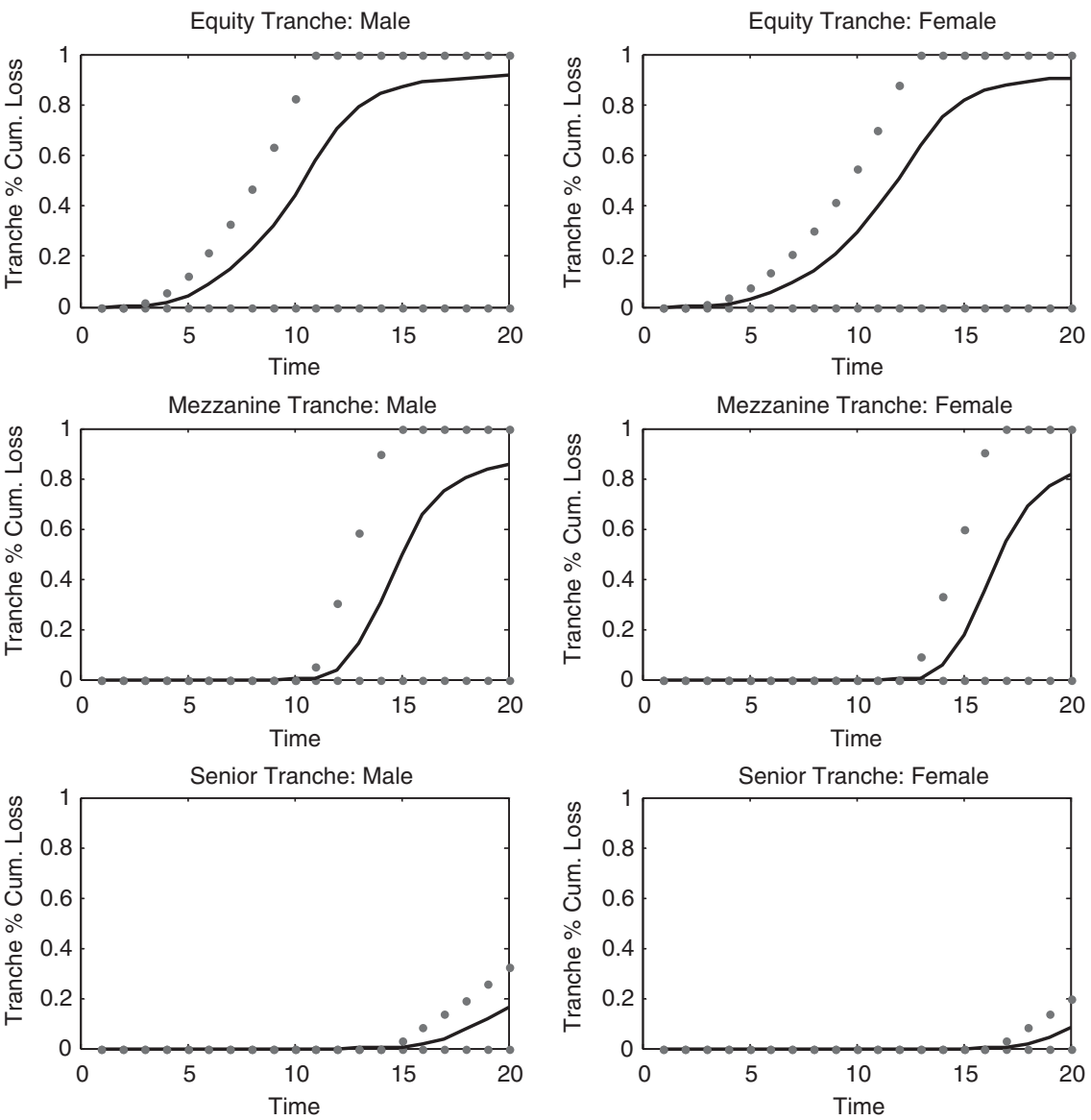

Figure 7. Expected cumulative tranche loss (solid), with 95 per cent bounds (dotted): 10 per cent, 10 per cent, 80 per cent Tranche Level; $L T V=60$ per cent, $\lambda=-1$ per cent.

In our numerical analysis, we first analyse the shortfalls for the provider when issuing a portfolio of RM products. We calculate the fair spreads for both male and female borrowers and different LTV of 50 per cent, 60 per cent, 70 per cent, 80 per cent and 90 per cent. Since the equity tranche investor absorbs the loss first, before other tranche investors, the fair spread in equity tranche is much higher than other tranches. The fair spreads for the three tranches are lower for female borrowers. This is because the life expectancy for women is longer. We further compare the fair spreads for the underlying RM portfolio with different LTV. As expected, the higher the LTV, the higher the fair spread is. Since the higher LTV may result in higher loss, the investor needs to bear more risk and requires more compensation. In addition, the change in spreads is more significant for the equity tranche investors and less significant for senior tranche investors. 

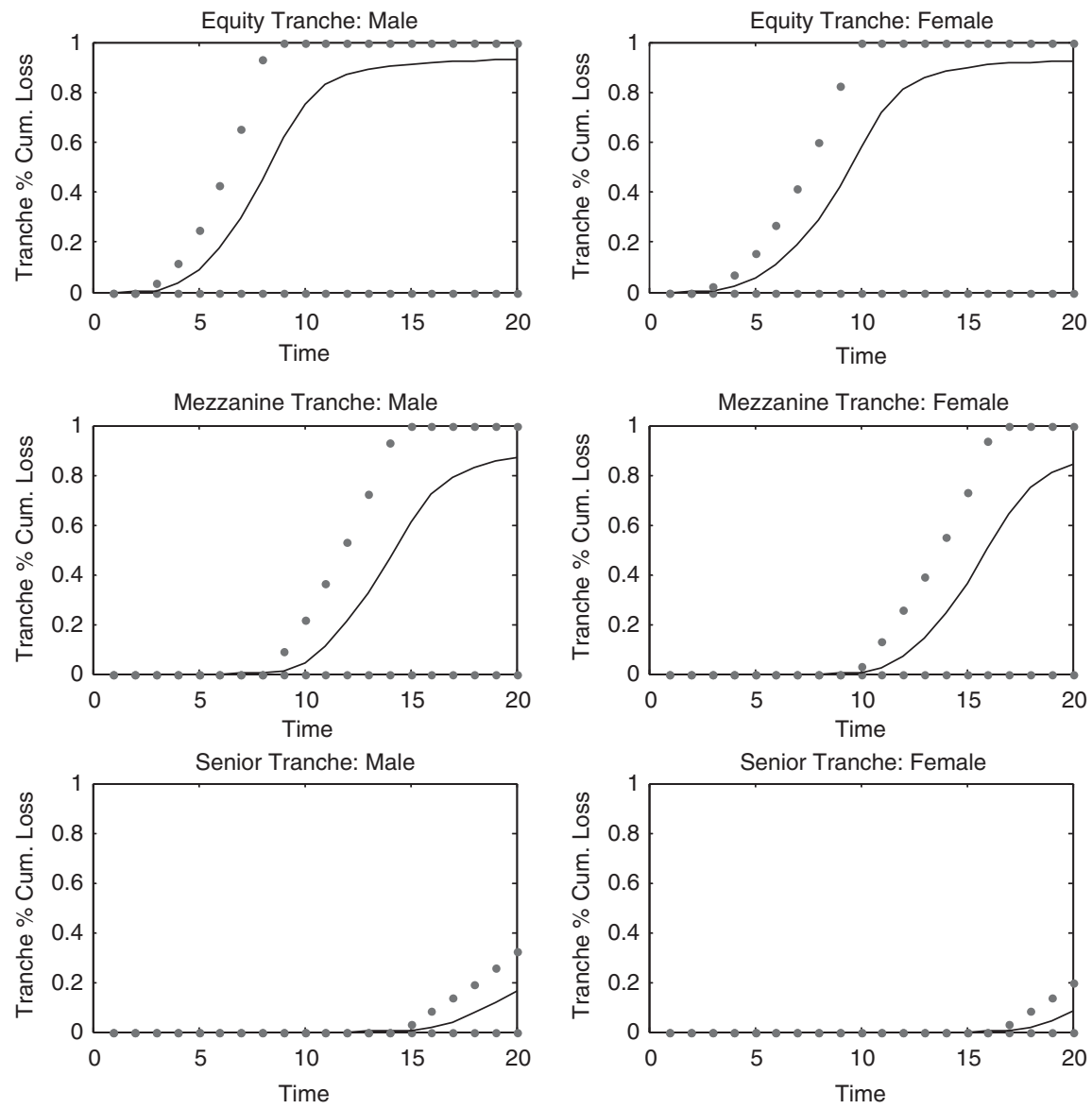

Figure 8. Expected cumulative tranche loss (solid), with 95 per cent bounds (dotted): 5 per cent, 15 per cent, 80 per cent Tranche Level; $L T V=60$ per cent, $\lambda=-1$ per cent.

Table 8 The effect of ignoring mortality dynamics on fair spreads for different tranches of CRMO

\begin{tabular}{|c|c|c|c|c|}
\hline$L T V(\%)$ & $R M$ borrower & $\begin{array}{c}\text { Equity }(\%) \\
5 \%\end{array}$ & $\begin{array}{c}\text { Mezzanine (\%) } \\
10 \%\end{array}$ & $\begin{array}{c}\text { Senior }(\%) \\
85 \%\end{array}$ \\
\hline \multirow[t]{2}{*}{50} & Male & 8.6230 & 4.8755 & 0.6473 \\
\hline & Female & 7.6736 & 4.2242 & 0.3783 \\
\hline \multirow[t]{2}{*}{60} & Male & 10.6757 & 5.7998 & 1.0221 \\
\hline & Female & 9.3162 & 4.9854 & 0.6392 \\
\hline \multirow[t]{2}{*}{70} & Male & 13.1404 & 6.7570 & 1.4511 \\
\hline & Female & 11.2018 & 5.7326 & 0.9367 \\
\hline \multirow[t]{2}{*}{80} & Male & 16.1689 & 7.7779 & 1.9320 \\
\hline & Female & 13.4081 & 6.4932 & 1.2660 \\
\hline \multirow[t]{2}{*}{90} & Male & 20.0576 & 8.8859 & 2.4657 \\
\hline & Female & 16.0721 & 7.2852 & 1.6248 \\
\hline
\end{tabular}


Table 9 The effect of mortality model risk on fair spreads for different tranches of CRMO $(\lambda=1 \%)$ LC model

\begin{tabular}{|c|c|c|c|c|}
\hline$L T V(\%)$ & $R M$ borrower & $\begin{array}{c}\text { Equity }(\%) \\
5 \%\end{array}$ & $\begin{array}{c}\text { Mezzanine (\%) } \\
10 \%\end{array}$ & $\begin{array}{c}\text { Senior }(\%) \\
85 \%\end{array}$ \\
\hline \multirow[t]{2}{*}{50} & Male & 8.3260 & 4.5770 & 0.4720 \\
\hline & Female & 7.2639 & 3.7695 & 0.2015 \\
\hline \multirow[t]{2}{*}{60} & Male & 10.2783 & 5.4755 & 0.7793 \\
\hline & Female & 8.8335 & 4.5249 & 0.3913 \\
\hline \multirow[t]{2}{*}{70} & Male & 12.5926 & 6.3910 & 1.1333 \\
\hline & Female & 10.6349 & 5.2436 & 0.6146 \\
\hline \multirow[t]{2}{*}{80} & Male & 15.3999 & 7.3515 & 1.5298 \\
\hline & Female & 12.7380 & 5.9664 & 0.8647 \\
\hline \multirow[t]{2}{*}{90} & Male & 18.9714 & 8.3789 & 1.9686 \\
\hline & Female & 15.2912 & 6.7153 & 1.1387 \\
\hline
\end{tabular}

The earlier HECM programme uses static mortality tables to calculate the loan value. We also investigate the effects of failing to capture the dynamics of mortality on securitisation of longevity risk for reverse mortgages. From the SPV point of view, ignoring mortality dynamic will overestimate the fair spread. In addition, we employ the LC model to calculate the fair spread. In most of the cases, the fair spread based on the LC model is lower. This is because the projected life expectancy using the CBD model is a little bit longer than that using the LC model. Thus, it implies that the use of the LC model will underestimate the fair spread to the investors.

The main contribution of this article is to illustrate a new structuring security of CRMO to transfer the risks for RM providers. We also provide a risk-neutral valuation framework for pricing the fair spreads in each tranche. Because RM products are growing increasingly popular in many developed countries, the design of CRMO and pricing methodology proposed in this article could benefit the practitioner to develop the capital market solution for dealing with the risk regarding RM products. However, the moral hazard problem may arise, by allowing lenders to securitise away their longevity and house price risk. Thus, equity tranche should be retained by the issuer, managing moral hazard by aligning the issuer's interests with those of the investor. Where this does not occur, as happened in the CDO market, the tranche structure will not mitigate moral hazard (see also Wills and Sherris ${ }^{19}$ ). Thus, the regulation issue regarding the moral hazard problem is worth studying to develop the capital market solution.

In the light of our analysis in this article, we also highlight some areas for further research. First, to deal with the mortality modelling for the elderly, we employ the discrete CBD model and employ the risk adjust measure to find the risk-neutral measure for pricing longevity-linked securities. However, the suitability of discrete mortality model for pricing longevity-linked securities is restricted, due to limitations in incorporating a risk adjustment into the mortality distribution. This method has been subject to criticism (see Cairns et al. ${ }^{23}$; Bauer and Russ, 2006). We can extend the pricing of CRMO to continuous time mortality models. Second, this research only takes into account the first two risks to illustrate the structure of CRMO because 
longevity risk and house price risk appear to be more significant due to the recent mortality improvement and house price dynamics. The structure of CRMO can also apply when taking into account interest rate risk. This can be achieved by incorporating a stochastic interest rate model. Taking into account interest rate risk is worth doing and we have done so for further research.

\section{References}

American Housing Survey for the United States. (2005) Current Housing Reports (August), U.S. Department of Housing and Urban Development and U.S. Census Bureau, p. 156.

Antolin, P. (2007) Longevity risk and private pensions, OECD Working Papers on Insurance and Private Pensions, No. 3, OECD Publishing.

Bauer, D. and Weber, F. (2007) Assessing investment and longevity risks within immediate annuities, Working Paper.

Bauer, D. and Russ, J. (2006) Pricing Longevity Bonds using Implied Survival Probabilities, Working Paper, from http:www.mortalityrisk.org.

Biffis, E. (2005) 'Affine processes for dynamic mortality and actuarial valuations', Insurance: Mathematics and Economics 37(3): 443-468.

Biffis, E. and Blake, D. (2009) Mortality-linked securities and derivatives, Discussion Paper PI-0829, The Pensions Institute, Cass Business School.

Biffis, E. and Blake, D. (2010) 'Securitizing and tranching longevity exposures', Insurance: Mathematics and Economics 46(1): 186-197.

Blake, D. and Burrows, W. (2001) 'Survivor bonds: Helping to hedge mortality risk', Journal of Risk and Insurance 68(2): 339-348.

Blake, D., Boardman, T. and Cairns, A. (2010) Sharing longevity risk: Why governments should issue longevity bonds, Pensions Institute Discussion Paper PI-1002.

Blake, D., Cairns, A.J.G., Dowd, K. and MacMinn, R. (2006) 'Longevity bonds: Financial engineering, valuation and hedging', Journal of Risk and Insurance 73(4): 647-672.

Blake, D., Dowd, K. and Cairns, A.J.G. (2008) 'Longevity risk and the grim reaper's toxic tail: The survivor fan charts', Insurance: Mathematics and Economics 42: 1062-1068.

Bühlmann, H., Delbaen, F., Embrechts, P. and Shiryaev, A.N. (1996) 'No-arbitrage, change of measure and conditional Esscher transforms', CWI Quarterly 9: 291-317.

Cairns, A.J.G., Blake, D. and Dowd, K. (2006) 'A two-factor model for stochastic mortality with parameter uncertainty: Theory and calibration', Journal of Risk and Insurance 73(4): 687-718.

Chang, C.C., Yang, S.S. and Huang, C.W. (2010) Pricing No-Negative-Equity Guarantees for Equity Release Products under a Jump ARMA-GARCH Model, 2010 Annual Conference of Insurance: Mathematics and Economics, Toronto.

Chen, H., Cox, S.H. and Wang, S.S. (2010) 'Is the home equity conversion mortgage in the United States sustainable? Evidence from pricing mortgage insurance premiums and non-recourse provisions using the conditional Esscher transform', Insurance: Mathematics and Economics 46(2): 173-185.

Crawford, G.W. and Fratantoni, M.C. (2003) 'Assessing the forecasting performance of regime-switching ARIMA and GARCH models of house prices', Real Estate Economics 31(2): 223-243.

Dahl, M.H. and Møller, T. (2005) 'Valuation and hedging of life insurance liabilities with systematic mortality risk', in Proceedings of the $15^{\text {th }}$ International AFIR Colloquium, Zurich, from http://www afir2005.ch.

Dahl, M.H. (2004) 'Stochastic mortality in life insurance: Market reserves and mortality-linked insurance contracts', Insurance: Mathematics and Economics 35(1): 113-136.

Dowd, K., Blake, D., Cairns, A. and Dawson, P. (2006) 'Survivor swaps', Journal of Risk and Insurance 73(1): 1-17.

Duan, J.C. (1995) 'The GARCH option pricing model', Mathematical Finance 5(1): 13-32.

Esscher, F. (1932) 'On the probability function in the collective theory of risk', Skandinavisk Aktuarietidskrift 15: $175-195$.

Foote, B.E. (2007) Reverse mortgages: Background and issues, Congressional Research Service Report. 
672

Gerber, H.U. and Shiu, E.S.W. (1994) 'Option pricing by Esscher transforms', Transactions of the Society of Actuaries 46: 99-191.

Human Mortality Database (HMD). (2010) Available at http:www.mortality.org.

Kutty, N.K. (1998) 'The scope for poverty alleviation among elderly home-owners in the US through reverse mortgages', Urban Studies 35(1): 113-130.

Lee, R.D. and Carter, L.R. (1992) 'Modeling and forecasting U.S. mortality', Journal of the American Statistical Association 87(419): 659-671.

Li, J.S-H., Hardy, M.R. and Tan, K.S. (2010) 'On pricing and hedging the no-negative-equity guarantee in equity release mechanisms', Journal of Risk and Insurance 77(2): 499-522.

Liao, H.H., Yang, S.S. and Huang, I.H. (2007) The Design of Securitization for Longevity Risk: Pricing under Stochastic Mortality Model with Tranche Technique, presented at the Third International Longevity Risk and Capital Market Solutions Symposium, Taipei.

Ma, S. and Deng, Y. (2006) Insurance premium structure of reverse mortgage loans in Korea, Working Paper.

MacMinn, R., Brockett, P. and Blake, D. (2006) 'Longevity risk and capital markets', Journal of Risk and Insurance 73(4): 551-557.

Milevsky, M.A. and Promislow, S.D. (2001) 'Mortality derivatives and the option to annuitize', Insurance: Mathematics and Economics 29(3): 299-318.

Miller, N. and Peng, L. (2006) 'Exploring metropolitan housing price volatility', Journal of Real Estate Finance and Economics 33(1): 5-18.

National Reverse Mortgage Lenders Association. (2007) Statistics.

Renshaw, A.E. and Haberman, S. (2003) 'Lee-Carter mortality forecasting with age-specific enhancement', Insurance: Mathematics and Economics 33(2): 255-272.

Schrager, D.F. (2006) 'Affine stochastic mortality', Insurance: Mathematics and Economics 38(1): 81-97.

Shan, H. (2008) Reverse mortgages: A closer look at HECM loans, Working Paper.

Sherris, M. and Wills, S. (2007) 'Financial innovation and the hedging of longevity risk', Asia Pacific Journal of Risk and Insurance 3(1): 52-64.

Siu, T.K., Tong, H. and Yang, H. (2004) 'On pricing derivatives under GARCH models: A dynamic GerberShiu approach', North American Actuarial Journal 8(3): 17-31.

Sun, D. (2009) Reverse Mortgages: Credit Risk and the No Negative Equity Guarantee, Thesis, School of Actuarial Studies Australia School of Business, University of New South Wales.

Tuljapurkar, S., Li, N. and Boe, C. (2000) 'A universal pattern of mortality decline in the G7 countries', Nature 405: 789-792.

Wang, L., Valdez, E.A. and Piggott, J. (2008) 'Securitization of longevity risk in reverse mortgages', North American Actuarial Journal 12(4): 345-371.

Wills, S and Sherris, M. (2010) 'Securitization, structuring and pricing of longevity risk', Insurance: Mathematics and Economics 46(1): 173-185.

Yang, S.S. and Huang, H.C. (2009) 'The impact of longevity risk on the optimal contribution rate and asset allocation for defined contribution pension plans', The Geneva Papers on Risk and Insurance-Issues and Practice 34(4): 660-681.

Zhai, D.H. (2000) Reverse mortgage securitizations: Understanding and gauging the risks, Special Report, Moody's Investors Service.

\section{About the Author}

Sharon S. Yang is Professor and Chairperson of the Department of Finance at the National Central University in Taiwan. She received her $\mathrm{PhD}$ in actuarial mathematics at Heriot-Watt University in the U.K. and her Masters degree in actuarial science at the University of Iowa in the U.S. Her research interests cover pricing and financial risk management for insurance and pension, mortality modelling, and pricing mortality-linked securities. Her research appears in Insurance Mathematics and Economics, the Journal of Risk and Insurance, Austin Bulletin and The Geneva Papers on Risk and Insurance-Issues and Practice. 


\section{Appendix}

In this appendix, we prove Equation (15). Under an $\operatorname{ARMA}(s, m)-\operatorname{GARCH}(p, q)$ process shown in Eqs. (8) and (9). First, we derive the risk-neutral return process for conditional mean.

$$
\begin{aligned}
M_{D Y_{t} \mid \Phi_{t-1}}^{Q}\left(z ; a_{t}\right) & =\frac{M_{D Y_{t} \mid \Phi_{t-1}}^{P}\left(z+a_{t}\right)}{M_{D Y_{t} \mid \Phi_{t-1}}^{P}\left(a_{t}\right)} \\
& =e^{\left(\mu_{t}-\frac{h_{t}}{2}\right)\left(z+a_{t}^{q}\right)+\left(\frac{h_{t}}{2}\right)\left(z+a_{t}^{q}\right)^{2}-\left(\mu_{t}-\frac{h_{t}}{2}\right) a_{t}^{q}-\left(\frac{h_{t}}{2}\right)\left(a_{t}^{q}\right)^{2}} \\
& =e^{\left(\mu_{t}-\frac{h_{t}}{2}\right) z+\left(\frac{h_{t}}{2}\right) z\left(2 a_{t}^{q}+z\right)} \\
& =e^{\left(\mu_{t}-\frac{h_{t}}{2}+h_{t} a_{t}^{q}\right) z+\left(\frac{h_{t}}{2}\right) z^{2}} .
\end{aligned}
$$

In order for $\mathbf{Q}$ to be an equivalent martingale measure, we need to have

$$
e^{r-g}=M_{D Y_{t} \mid \Phi_{t-1}}^{Q}\left(1, a_{t}\right)=\frac{M_{D Y_{t} \mid \Phi_{t-1}}^{P}\left(1+a_{t}\right)}{M_{D Y_{t} \mid \Phi_{t-1}}^{P}\left(a_{t}\right)}
$$

Therefore,

$$
\begin{aligned}
& r-g=\mu_{t}-\frac{h_{t}}{2}+h_{t} a_{t}^{q}+\frac{h_{t}}{2} \\
& \Rightarrow a_{t}^{q}=\frac{r-\mu_{t}-g}{h_{t}}
\end{aligned}
$$

where

$$
E^{Q} e^{D Y_{t}}=e^{\left(\mu_{t}-\frac{h_{t}}{2}+h_{t} a_{t}^{q}\right) z+\left(\frac{h_{t}}{2}\right)}=e^{\left(r-g-\frac{1}{2} h_{t}\right) z+\frac{1}{2} h_{t}}
$$

Thus $\left\{D Y_{t}^{Q}, t \geqslant 0\right\}$ is also a Brownian motion with drift $r-g-(1 / 2) h_{t}$ and volatility $h_{t}$ under the measure $\mathbf{Q}$. Second, we prove that the volatility $h_{t}$ under the measure $\mathbf{Q}$, suppose $\left\{\varepsilon_{t}\right\}$, follows a $\operatorname{GARCH}(p, q)$ process with the conditional distribution $F\left(\bullet \mid 0, h_{t}\right)$, given $\Phi_{t-1}$ being a normal distribution with mean zero and variance $h_{t}$. Then, the conditional distribution of $D Y_{t}$ given $\Phi_{t-1}$ follows mean $r+\eta \sqrt{h_{t}}-g-$ $1 / 2 h_{t}$ and variance $h_{t}$. Hence under $\mathbf{Q}$, the conditional distribution of $D Y_{t}$ is a normal distribution with conditional mean $r-g-1 / 2 h_{t}$ and conditional variance $h_{t} . h_{t}$ is expressed as

$$
h_{t}=w+\alpha_{1} \varepsilon_{t-1}^{2}+\beta_{1} h_{t-1}
$$

It is important to note that the conditional distribution of $\varepsilon_{t}$ given $\Phi_{t-1}$ is a normal distribution with mean $-\eta \sqrt{h_{t}}$ and variance $h_{t}$ under the martingale pricing 
probability measure $\mathbf{Q}$. Define a new random variable $\xi_{t}=\varepsilon_{t}+\eta \sqrt{h_{t}}$. Then, under $\mathbf{Q}$, the conditional distribution of $\xi_{t}$ given $\Phi_{t-1}$ is a normal distribution with mean zero and variance $h_{t}$. Thus, under $\mathbf{Q}$, we can write the conditional variance process is given by:

$$
h_{t}^{Q}=w+\alpha\left(\xi_{t-1}-\eta \sqrt{h_{t-1}^{Q}}\right)^{2}+\beta h_{t-1}^{Q} .
$$

The conditional variance process under $\mathbf{Q}$ is the same as those in Duan ${ }^{44}$. Finally, let $\eta$ is risk premium. Under the risk-neutral conditional Esscher measure $\mathbf{Q}$, we can write the return process as

$$
\begin{aligned}
& Y_{t}^{Q}=r-g-\frac{h_{t}^{Q}}{2} \\
& h_{t}^{Q}=w+\sum_{i=1}^{q} \alpha_{i}\left(\xi_{t-i}-\eta \sqrt{h_{t-i}^{Q}}\right)^{2}+\sum_{j=1}^{p} \beta_{j} h_{t-j}^{Q} .
\end{aligned}
$$

\footnotetext{
${ }^{44}$ Duan (1995).
} 